\title{
Simulation of a model DC-DC converter with cascaded via improvement PFC with boost converter and THD using multiple loads
}

\section{Anchal Yadav* and Pratibha Tiwari}

\author{
Department of Electrical Engineering, \\ VIAET, \\ Sam Higginbottom University of Agriculture, \\ Technology and Sciences, \\ Allahabad, 211007, UP, India \\ Email: Anchalyadav992@gmail.com \\ Email: Pratibha.tiwari@shuats.edu.in \\ *Corresponding author
}

\begin{abstract}
In this paper proposed a converter which improves the total harmonic distortion (THD) and power factor correction (PFC). In proposed DC side boost converter accompany through the forward converter. In this research, conventional rectifier's diode-bridge and rectifying bridge linked with boost converters which given good performance of the system. So it is concluded the improvement of total harmonic factor and power factor through the solution of the simulation. It is reduce the input current with proposed converter, and minimise the current harmonic. Instantly enlarge power semiconductors devices with utilisation of power electronics systems, which generate broad and new applications ranges like, aerospace, commercial, industrial and traction. The semi-converter device connected with current drawn which given line distortion results in high level of harmonics and low power factor. More analysis of these problems always connected with multiple loads and nonlinear utilisation of load input current with total harmonic distortion.
\end{abstract}

Keywords: power factor correction; PFC; forward converter; AC/DC converter; DC motor drive; boost converter; total harmonic distortion; THD.

Reference to this paper should be made as follows: Yadav, A. and Tiwari, P. (2020) 'Simulation of a model DC-DC converter with cascaded via improvement PFC with boost converter and THD using multiple loads', Int. J. Digital Signals and Smart Systems, Vol. 4, Nos. 1/2/3, pp.147-170.

Biographical notes: Anchal Yadav is doing PhD in Electrical Engineering at Sam Higgin bottom University of Agriculture Science And Technology, Prayagaraj. She has done her MTech in Electrical Engineering (Control and Instrumentation) from Sam Higgin bottom University of Agriculture Science And Technology, Prayagaraj in 2016 with silver medal. In 2014, she has done BTech in Electronics and Instrumentation Engineering from the Integral University Lucknow with 1st division with honours. She has very good knowledge of MATLAB/SIMULINK and she has published almost 15 papers, some in journals and some is conference of during research. She has done lots of workshop and seminar related the course.

Pratibha Tiwari is an Assistant Professor in the Department of Electrical Engineering at Sam Higgin bottom University of Agriculture Science and Technology, Prayagaraj. She has done BTech in United College of 
Engineering, Prayagraj and MTech in Motilal Nehru National Institute of Technology, Prayagaraj. She obtained degree of $\mathrm{PhD}$ in Electrical Engineering at Sam Higgin bottom University of Agriculture Science and Technology, Prayagaraj. She has done the work as advisor more than 20 students of the MTech and 50 above student of BTech. She published 50 above research paper and she has experience of teaching 15years. She has very good expert of control system.

This paper is a revised and expanded version of a paper entitled 'Simulation of a model DC-DC converter with cascaded via improvement PFC with boost converter and THD using multiple loads' presented at International Conference on Sustainable Energy, Electronics and Computing-SEEMS, Greater Noida, 26-27 October 2018.

\section{Introduction}

Interchange the power between AC-DC conversions and again used for the next DC output with additional stages. The conversion of AC-DC is most integral part of equipment's which related to the equipment's (Maksimovic and Cuk, 1991). In this conversion we are using rectifiers or Diode Bridge. Due to the non-sinusoidal, according to the nature total harmonics always high and power factor is low. Two factors that evaluate of electrical system power quality. Then we are trying to consume the power through electrical system for maintaining the power factor. The quantity of feed harmonics explore by drawn current of the system which generated by total harmonics distortion.

We need to find out that contains which makes system progress change according with total harmonics and less power factor, in diode rectifier input current collect some odd harmonics parts which became very poor results of power factor. If we have to serious then we should neglect the diode bridge rectifier which produces by conventional converter these has very serious effect. So there is having competition to achieve rectification which is very close to unity power for low input current distortion. In some addition regulated DC output very useful for the AC-DC supplies which design some main criteria to the system. It is very easy to change with bridge diode with some additional converter for this distortion and low input current. Switches mode power factor conversion with AC-DC for high efficiency and power density always used end of front converters. These rectifiers using boost topologies. In this paper rectifier converter with boost and forward converter have been proposed. Its input maintains low power factor and distortion of harmonics analyses has been made. It is using with single phase diode bridge rectifier with boost and forward converter.

The study made using Simulink MATLAB. The detailed less power factor and total harmonics distortion has been done. Further proposed converter with multiple loads is analysed.

\section{Layout of the research}

In this paper divided by mainly seven sections which are as follows: 
Section 2 is literature review and the previous work done by another authors which has knowledge of power factor and harmonics analysis of rectifier (cascaded with dc to dc converter) with multiple loads is discussed.

This Section 3 gives brief information about how the technological advancement has led and made strong base of power converters and power factor and total harmonic distortion (THD) for dc-dc converter model with simulation and here also discussed active and passive type filters. Section 4 presents the proposed rectifiers converter with boost converter and forward converter. In this section focused on the design and modelling of the rectifiers which used here.

Section 5 discussed simulation of circuit diagram cascaded rectifier boost converter and forward converter with RL load. there is also explained about three-phase diode rectifiers with Table 1 three phase diode rectifier used parameters in Simulink and another table is Table 2 various parameter of diode rectifier measured value. In this section we are using input current and input voltages with harmonic spectrum. Another sub-section of the three-phase controlled rectifier with Table 3 rectifiers in Simulink and some FFT graph which is given power factor results and input current in THD.

Section 6 explained about the proposed model using multiple loads which showing in figure of Simulink model connect with multiple loads with Table 5 for one loop controller-based dc-dc converter used simulating and the FFT graphs of the output voltage with dc motor and RL load. In Table 6 the various parameter of one cycle control dc-dc converter measured a value with Figure 7(h) - input current THD.

In Section 7 using proposed model with multiple loads which is find out the value of total harmonics distortion and power factor correction. When applied multiple loads in model we got different desired result and this different result we can used industry and plant. Section 8 conclusions are drawn from the work done and helpful for the future scope of the research topic.

\section{Literature and review}

Real power (watts) creates real work these are the energy transfer components. The power requires of reactive power which analysis the magnetic field for real work which used for lost power, apparent power always assume total power (Bang and Park, 2018).

Correction is a method of improving power factor in a system by using suitable devices. The objective of this circuit correct the power factor which makes the input power supply a resistor. So, when ratio of voltage and current is constant, then power factor will be 1.0 (Baek et al., 2017).

In this paper have some problem with some particular companies; they can not manage with harmonics currents so adding here come capacitors or inductors which manage the load (Badawy et al., 2016).

To quantify the distortion, the term THD is used, design some filters for only current line frequency 50 or $60 \mathrm{~Hz}$. If we will be use pure form of current and voltage it is reduce distortion and the harmonics, and a non-sinusoidal (Yao et al., 2015).

We are using equation related to the power factor wind turbine in Sections 2 and 4 with multiple variables which are very useful in this research. After this entire scenario we need to add some special values of tables which have Table 1 to Table 6 in 
Sections 5 to 6 . It is showing the values of parameters and modes. So we can see equations (1) to (10) explain in section-with lots of varying status of corrections. So how to work converters we can assume easily. Then next Sections 4, 5, 6 given the proposed model with results of simulation and FFT graphs.

\section{Power factor and THD for DC-DC converter}

In this network, we are defined as:

$$
P F=\text { Real power/Apparent power }
$$

We know that here current and voltage ratio is constant then the input is good and power factor 1.0. Real power (watts) given real work and energy transfer component.

\subsection{THD with power factor correction (PFC)}

The ratio of this distortion depend on these equations:

$$
P F=P O W E R /\left(V_{r m s} * I_{r m s}\right)=W A T T / V . A
$$

$P$ is the real input power and $V_{r m s}$ and $I_{r m s}$ are the root mean square (RMS) voltage and current of the load. If there have some problems in a ratio of a using network and its low then presence of all network in whole system may be disordered (Wei and Batarseh, 1998).

Disadvantage low power factor:

- voltage regulation is low

- $\quad$ short efficiency

- voltages misbehave

- line loss

- draw more current.

THD characterise by the real quantity power of electric systems. We can write:

$$
T H D=\sqrt{\left\{\left(\frac{I_{r m s}}{I_{1}}\right)^{2}-1\right\}}
$$

where $I_{r m s}$ is the $r m s$ value of input current and $I$, is the fundamental frequency component.

\subsection{Switch mode power supply for PFC}

A typical switched-mode power supply first makes a DC bus, using a bridge rectifier or similar circuits. The output voltage is then derived from this DC bus. The problem with this is that the rectifier is a nonlinear device, so the input current is highly nonlinear.

That means the input current has energy at harmonics of the frequency of the voltage. This filter requires large-value high-current inductor however, which are bulky and expensive. 


\subsection{Harmonics standards for AC line}

The term is the ratio of the harmonic components of voltage (or current) to the voltage (or current) of the fundamental.

$$
H F=I H / I S 1=\sqrt{(I 2 S-I 2 S 1) / I S 1}
$$

where

$H F$ is harmonic factor

$I H \quad$ is RMS value of the entire harmonic combined

IS1 is the fundamental component

Is is the RMS value of input supply current.

\section{Conventional rectifier converters}

In this conventional rectifier converter which drives AC-DC, these have many uses. When we exploring all the system we got high voltage in a components which given direct supplies and here current and transmission system is mode on.

Figure 1 Basic converters

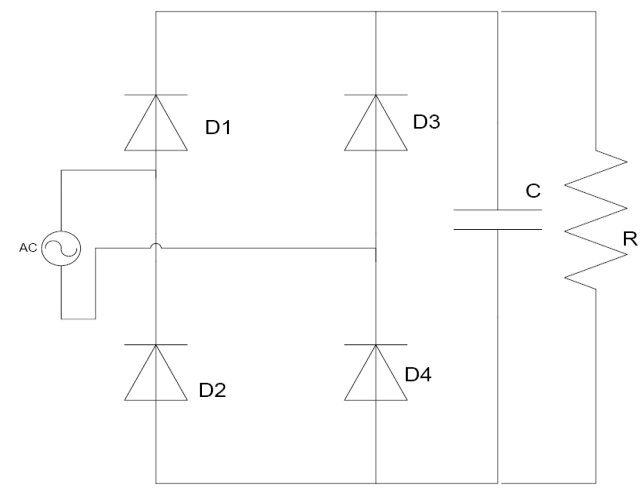

PFC is two types:

A passive PFC with total harmonics distortion

B active PFC with total harmonics distortion.

\subsection{Passive PFC with total harmonics distortion}

The passive PFC circuitry uses only passive components - an inductor and some capacitors. Passive PFC corrects the power factor to 0.7-0.85. A passive PFC rarely achieves low THD.

The passive techniques normally use a simple line-frequency LC to both extend the current conduction angle and reduce the THD of the input current of the diode-capacitor rectifiers. Passive PFC requires that the AC input voltage be set manually. 
Here the most common types of passive PFCs:

- $\quad$ capacitor input filter-also called the Pi filter; it removes unwanted frequencies from a signal

- valley-fill PFC - this power factor corrector can be used in low-power application, where a high effective ripple voltage on DC output can be tolerate.

\subsection{Active PFC with total harmonics distortion}

Technically speaking, the term 'active PFC', refer to the method of increasing PF by using active electronic circuits with feedback that control the shape of the drawn current. Active PFC offers better THD and is significantly smaller and lighter than a passive PFC circuit.

The preferable type of is active PFC since it provides more efficient power frequency. Active PFC use a circuits to correct power factor, active PFC is able to generate a theoretical power factor of over $95 \%$.

Active PFC functions include:

- $\quad$ active wave shaping of the input current

- $\quad$ filtering of the high frequency switching

- feedback sensing of the source current for waveform control

- feedback control to regulate output voltage.

\section{Proposed rectifiers converter}

Figure 2 showed the proposed AC-DC converter cascade with boots and a forward converter.

Figure 2 Proposed converter

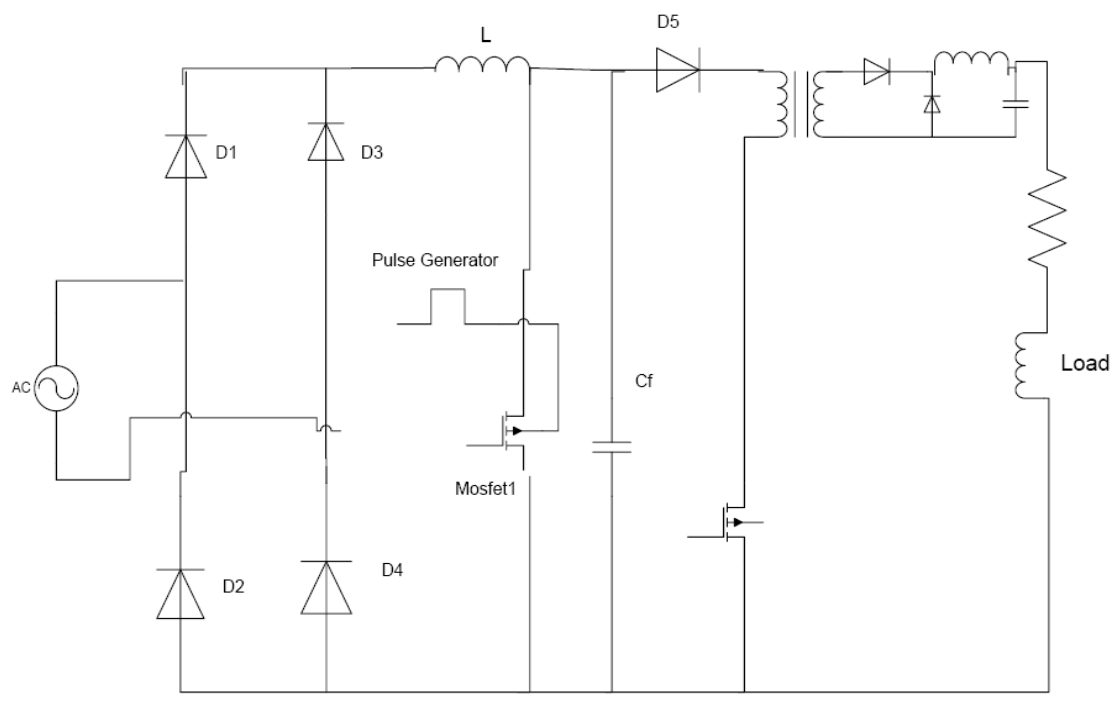


If we used boost chopper circuits, it is good for the constructing PFC to switching devices. Its characteristics are very good for the sinusoidal current waveform.

Sometimes we improved the output but some previous values of THD will b same like another results in $27 \%$. So reduce this fault by using a further forward converter in this analysis. Figure 2 discuss about the topology of the forward converter.

\subsection{Boost converter rectifier}

The buck-boost converter voltage stress $\left(V_{i n}+V_{o}\right)$. Sometimes its increase output of voltage which is very helpful for the THD and PFC.

Figure 3 Boost converter

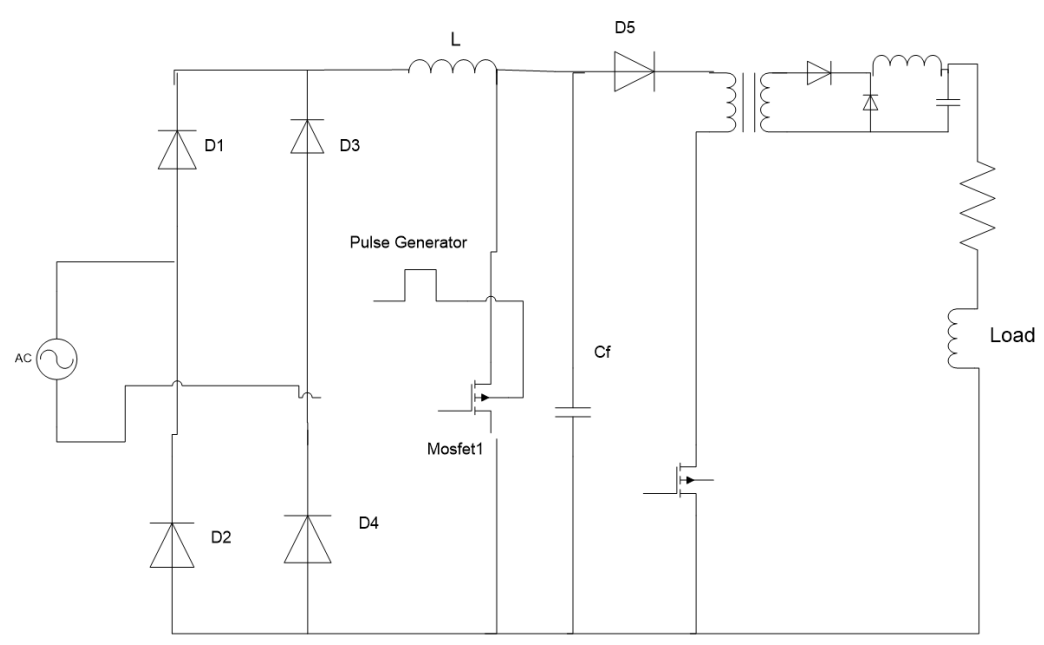

Equation calculate system initial values of a current of boost regulator which is use power balance equation:

$$
P_{\text {in }}=P_{\text {out }} / \eta
$$

In this case of a DC-DC converter, input and outputs power of product connected by currents and voltages values. Then adding the triangular ripple current, so equation:

$$
I_{\text {in }}=I_{\text {out }} \times\left(V_{\text {out }} / V_{\text {in }}\right) \times 1 / \eta+\Delta 1 / 2
$$

When boost converter is working, the input current will be always large, then the load current $\left(I_{\text {out }}\right)$. Since the output voltage of a boost is always greater than the input voltage, the input current must be greater than the load current.

The conversion of energy - the input power will be equal to the output power plus the losses.

\subsection{Maximum output voltage}

Limitation on the maximum output voltage for the boost is the maximum rated voltage of the MOSFET and or diode. The duty ratio defined as the on-time of the MOSFET divided by the total switching period. Damper on output voltage for the boost is a voltage of the diode or MOSFET. 
So, the correlation of the boost converter can be written:

$$
D=1-V_{\text {in }} \times \eta / V_{\text {out }}
$$

\subsection{Forward converter rectifiers}

We know that forward converter like a dc-dc converter. It is designed by high output power with high efficiency. Forward converter like dc-dc converter, behave like the fly-back and half bridge converter can supply either high or low input voltage and provide electrical isolation via a transformer. Forward converter design can high output power along with high energy efficiency. Forward converter behaves like step down converter with pre switched voltage transformation.

Figure 4 Forward converter

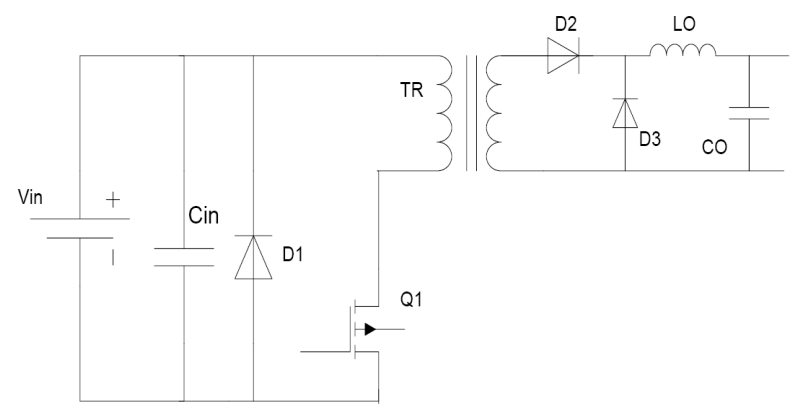

Its duty cycle can exceed $50 \%$, making its suitable for low-cost dc-dc converters that operate from a wide range of input voltage and deliver widely varying outputs. The transferor med input voltage is applied to the secondary windings. This serves to charge the choke.

A linearly increasing current flows through the choke and the load. So, a relationship described the balancing scenario of turn's ratio and the duty cycle.

$$
D C=N_{1} / N_{2} \times V_{o} / V_{i}
$$

Followed by the transformer the productive currents are given by:

$$
\begin{aligned}
& I_{e f f, \mathrm{sec}}=I_{o} \times \sqrt{D C} \\
& I_{\text {eff }, \text { prim }}=I_{o} \times N_{2} / N_{1} \times \sqrt{D C}
\end{aligned}
$$

Often used in dc-dc converter modules for power levels below $100 \mathrm{w}$, single transistor resonant reset forward converter are also useful for dc-dc converts with adjustable output voltages. Derived from the buck topology, the signals transistor forward converter employs a transformer and thus a means of galvanic isolation as well as voltage step-up or step-down, which makes it a good choice for offline application requiring both.

\section{Simulation model}

Here investigate the performance of the different AC-DC converter. PFC and THD are related to the simulation of the basic converter of the single phase. Somewhere we used cascade with boost and further modified with the forward converter. 
Figure 5 Simulation of circuit diagram cascaded rectifier boost converter and forward converter with RL load (see online version for colours)

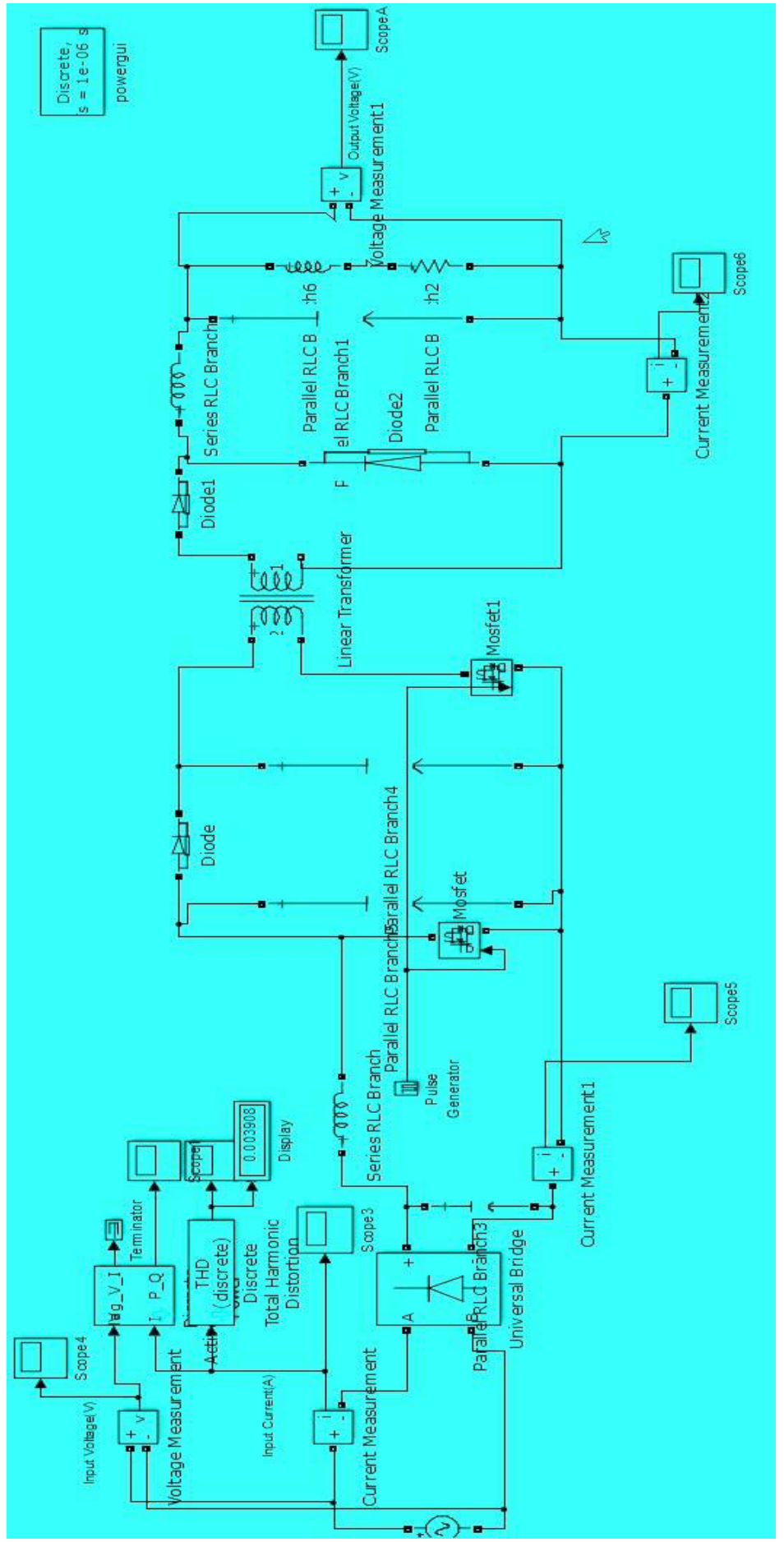




\subsection{Three-phase diode rectifiers}

Here draw the user parameter in Table 1, where all the value of the presence. After that, we know the how much improvement is calculated in given impute current waveform.

Table 1 Three phase diode rectifier used parameters in Simulink

\begin{tabular}{lc}
\hline Supply voltage (neutral phase) & $230 \mathrm{v}$ \\
Voltage frequency (source) & $60 \mathrm{~Hz}$ \\
Capacitor (DC-link) & $500 \mu \mathrm{F}$ \\
Load (resistance) & $30 \Omega$ \\
\hline
\end{tabular}

Here, THD with the help of FFT with the model of cascade simulation with a motor load. We are preferred here boost converter for a better output and it is given.

Input current in another form.

Table 2 Various parameter of diode rectifier measured value

\begin{tabular}{lccc}
\hline Active power $(P)$ & Apparent power $(s)$ & $P . F$ & Current $T H D$ \\
\hline 3,354 & 2,331 & 0.88 & $24 \%$ \\
\hline
\end{tabular}

\subsection{Three-phase controlled rectifier}

Then further show THD in percentage which is reduced $153 \%$ to $24 \%$. So it is all depends on the loads and converters.

Table 3 Rectifiers in Simulink

\begin{tabular}{lc}
\hline Supply voltage (neutral phase) & $230 \mathrm{~V}$ \\
Voltage frequency (source) & $60 \mathrm{~Hz}$ \\
Load (resistance) & $30 \Omega$ \\
Firing angle $\alpha$ & 30 degree \\
\hline
\end{tabular}

We are known that all details of the spectrum graph of input current, how it is improving the THD and PFC. In conventional AC-DC converter power factor is 0.8 and the AC-DC converter with boost converter and PF 0.899 . When boost converter connecting with $\mathrm{AC}$ to DC rectifiers THD automatically less and its increase inputs values with boost up output DC voltage. So, now the output is easily improved but still, THD is $27 \%$. Proposed converter is given good output with good characteristics by the current waveform in ac line phase and fixed dc voltage can acquire power factor is $0.99 \%$.

Table 4 The various parameter of control rectifier measured the value

\begin{tabular}{lccc}
\hline Active power $(P)$ & Apparent power $(s)$ & $P F$ & Current THD \\
\hline 2,432 & 2,989 & 0.9 & $27 \%$ \\
\hline
\end{tabular}


Figure 6 (a) Input current (b) Input voltage (c) Output voltage (d) Input current in the harmonic form (e) Harmonic spectrum of an input voltage (f) Harmonic spectrum of an output voltage (g) Input current THD (h) Result of input PF (see online version for colours)

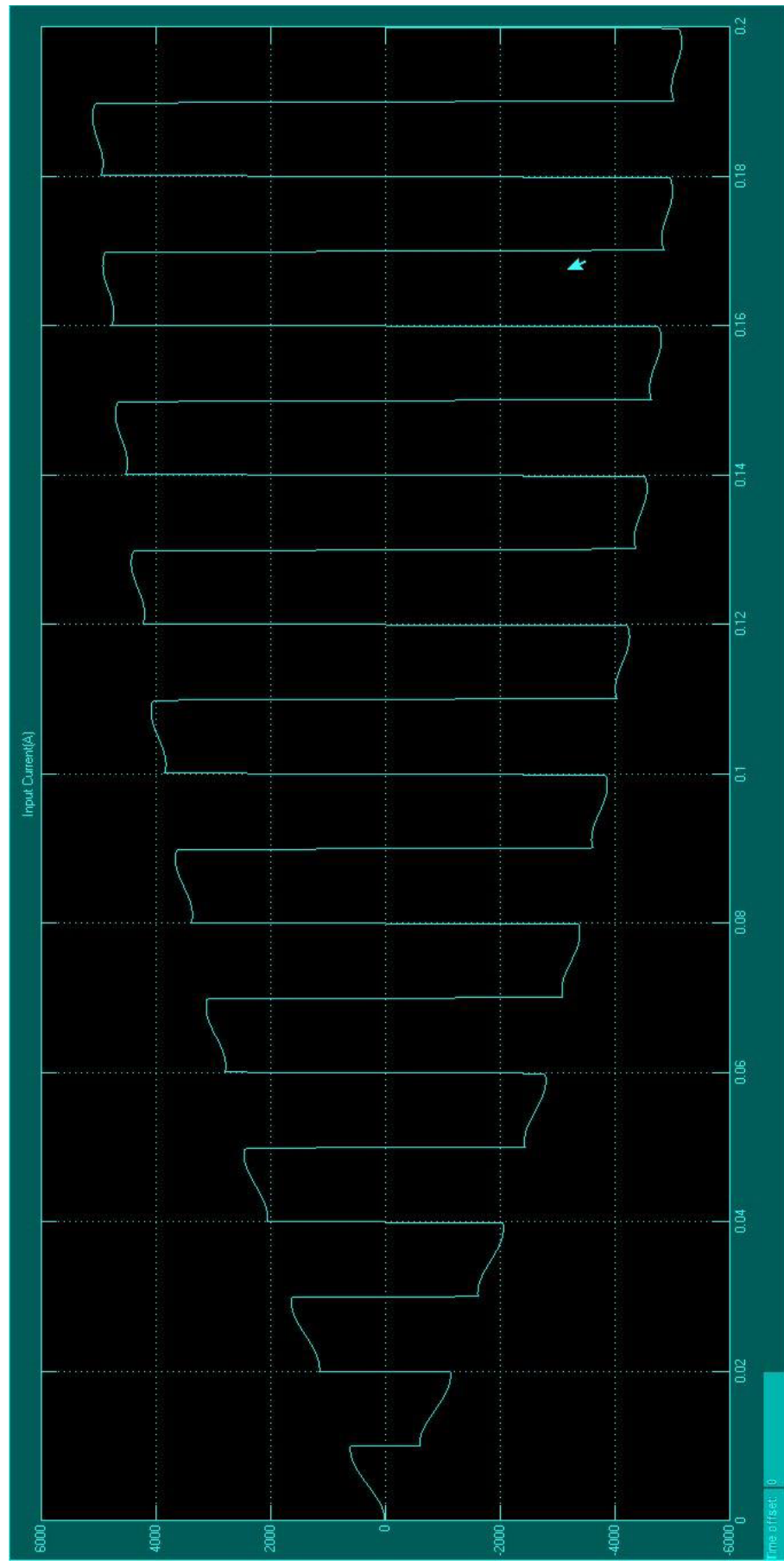

(a) 
Figure 6 (a) Input current (b) Input voltage (c) Output voltage (d) Input current in the harmonic form (e) Harmonic spectrum of an input voltage (f) Harmonic spectrum of an output voltage (g) Input current THD (h) Result of input PF (continued) (see online version for colours)

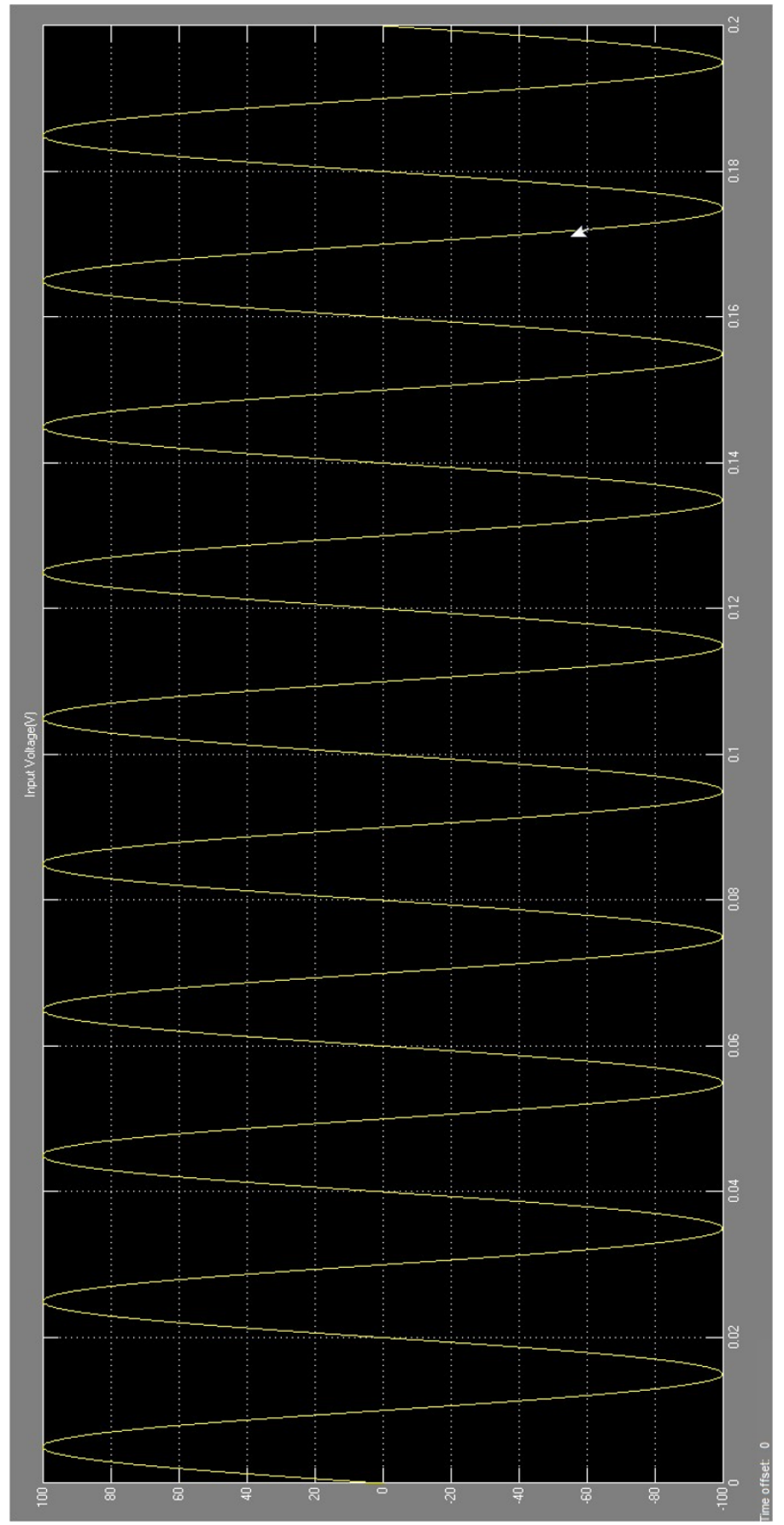

(b) 
Figure 6 (a) Input current (b) Input voltage (c) Output voltage (d) Input current in the harmonic form (e) Harmonic spectrum of an input voltage (f) Harmonic spectrum of an output voltage (g) Input current THD (h) Result of input PF (continued) (see online version for colours)

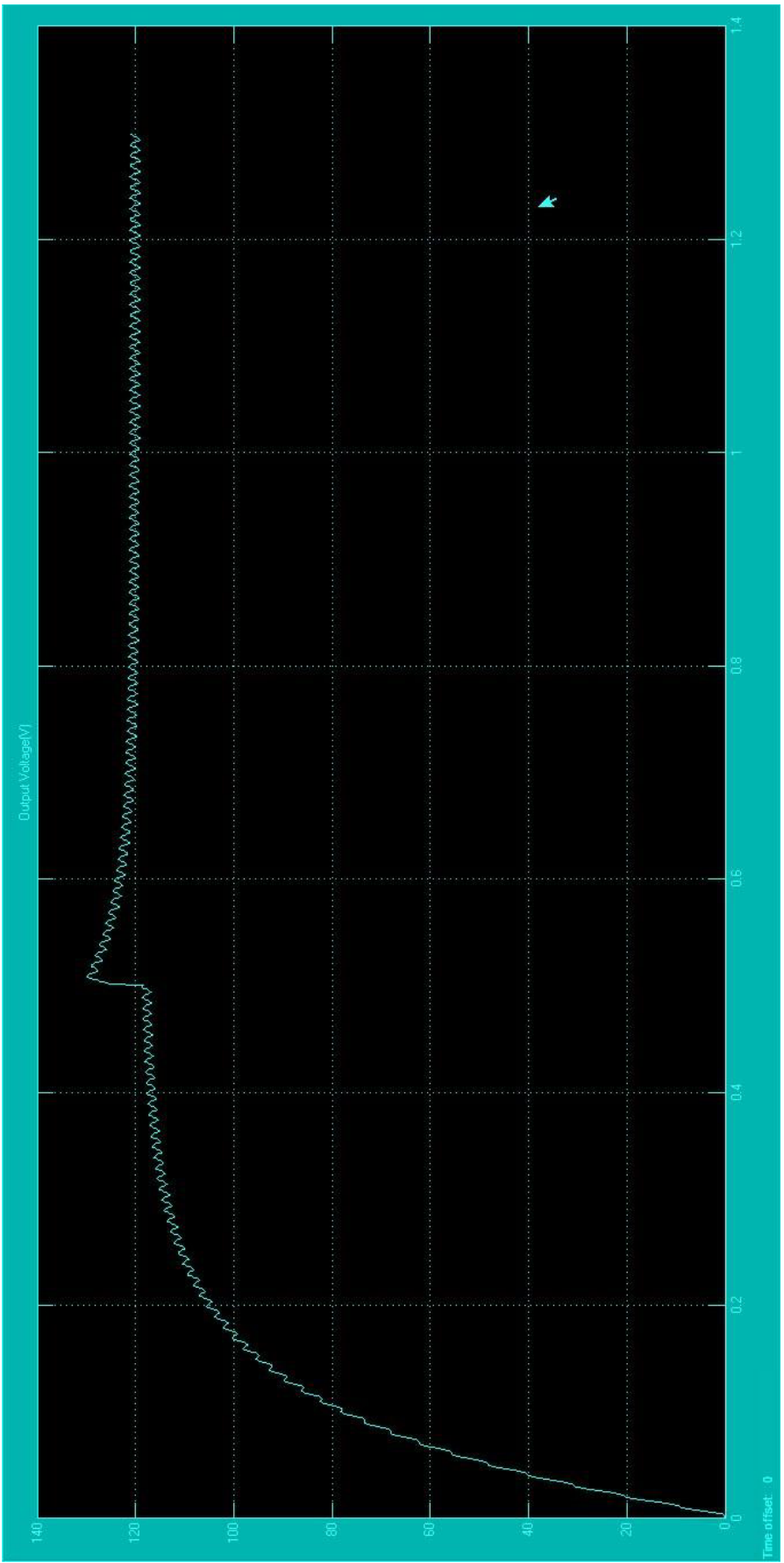

(c) 
Figure 6 (a) Input current (b) Input voltage (c) Output voltage (d) Input current in the harmonic form (e) Harmonic spectrum of an input voltage (f) Harmonic spectrum of an output voltage (g) Input current THD (h) Result of input PF (continued) (see online version for colours)

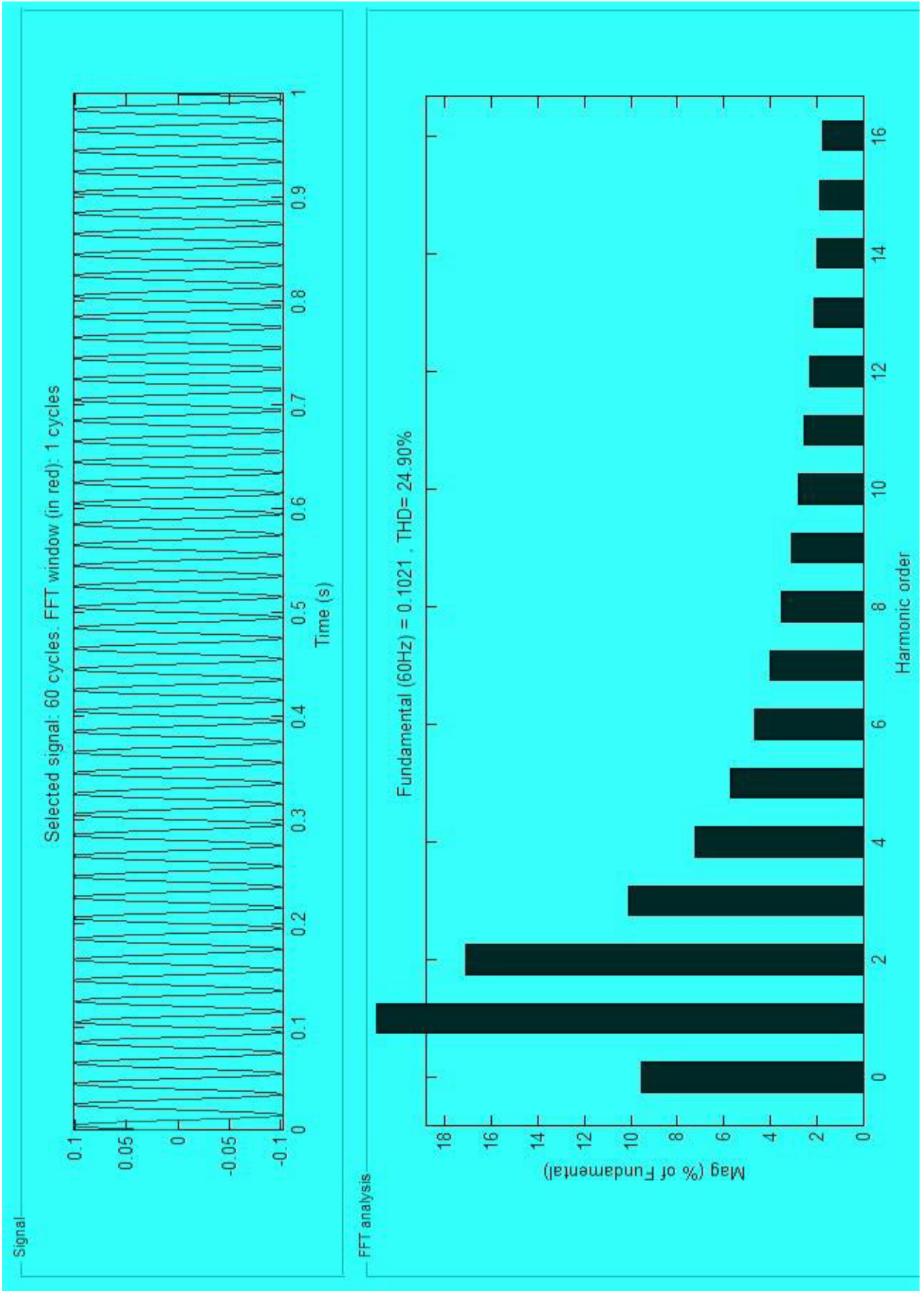

(d) 
Figure 6 (a) Input current (b) Input voltage (c) Output voltage (d) Input current in the harmonic form (e) Harmonic spectrum of an input voltage (f) Harmonic spectrum of an output voltage (g) Input current THD (h) Result of input PF (continued) (see online version for colours)

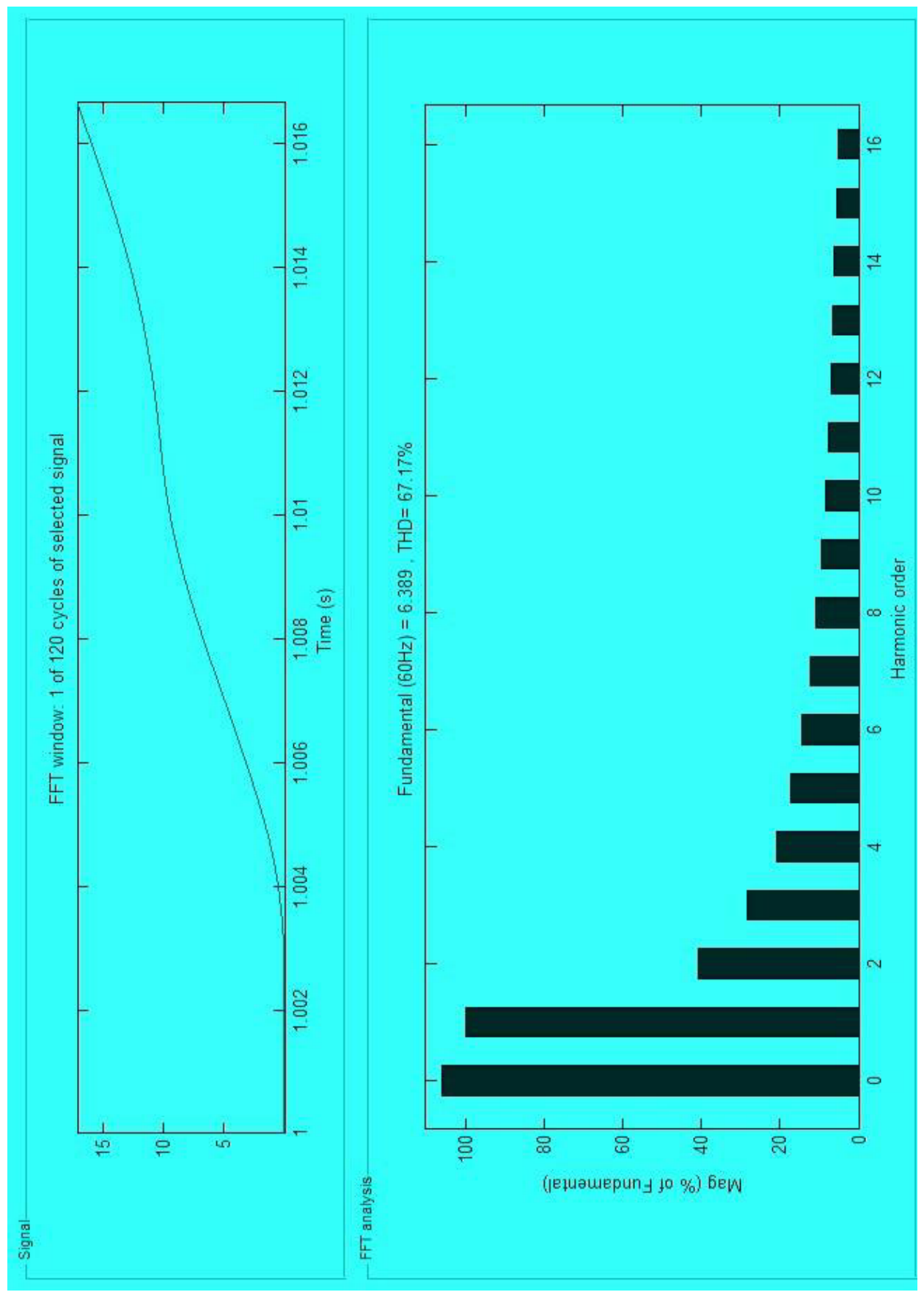

(e) 
Figure 6 (a) Input current (b) Input voltage (c) Output voltage (d) Input current in the harmonic form (e) Harmonic spectrum of an input voltage (f) Harmonic spectrum of an output voltage (g) Input current THD (h) Result of input PF (continued) (see online version for colours)

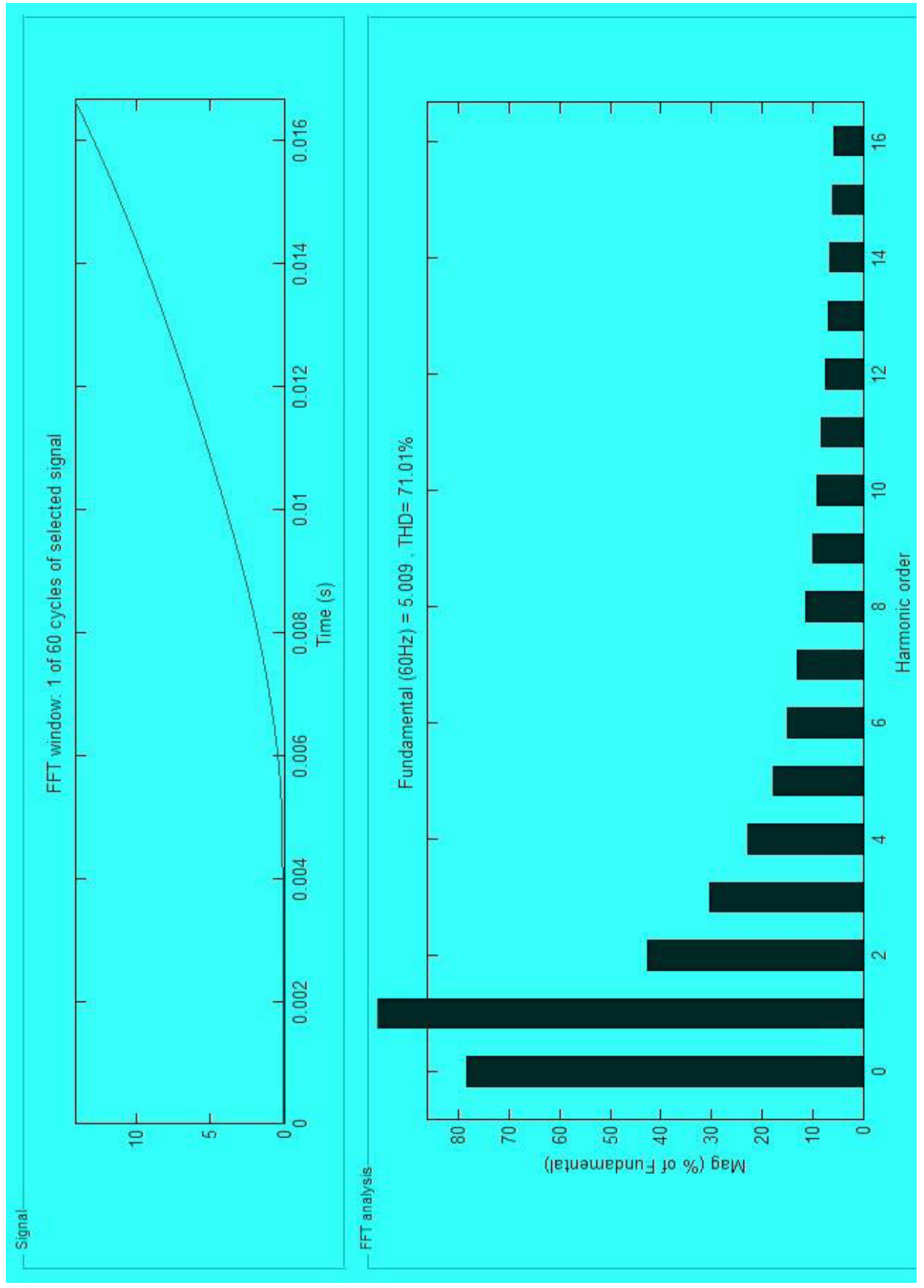

(f) 
Figure 6 (a) Input current (b) Input voltage (c) Output voltage (d) Input current in the harmonic form (e) Harmonic spectrum of an input voltage (f) Harmonic spectrum of an output voltage (g) Input current THD (h) Result of input PF (continued) (see online version for colours)

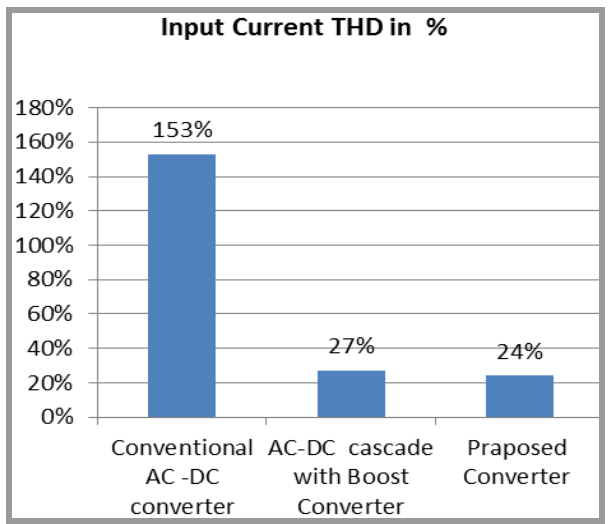

$(\mathrm{g})$

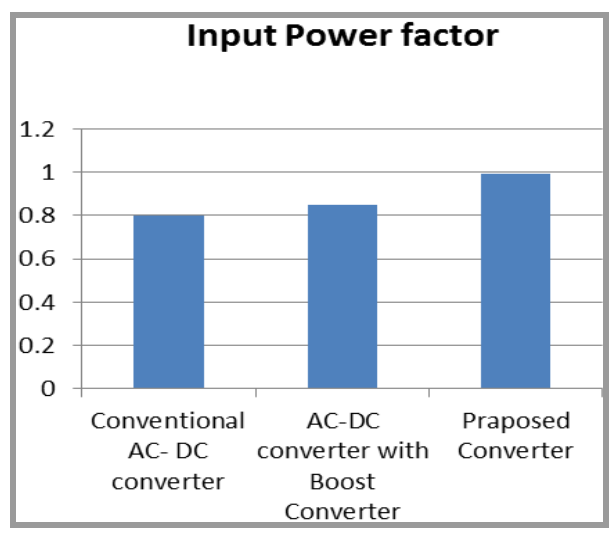

(h)

\section{Proposed model using multiple loads}

We explore the whole scenario of the PFC and a THD in the different term. Harmonic given nonlinear loads and segment are presented in this system. Basically, power factor linked to the harmonic in this whole system. So, the proposed model showing here three loads, which are load and two motors. Applies to those ac loads where the current is not analogous to the voltage.

Table 5 For one loop controller-based DC-DC converter used simulating

\begin{tabular}{lc}
\hline Supply voltage (neutral phase) & $230 \mathrm{~V}$ \\
Voltage frequency (source) & $60 \mathrm{~Hz}$ \\
Boost reactance of inductance & $2 \mathrm{mH}$ \\
Capacitor (DC-link) & $500 \mu \mathrm{F}$ \\
Switching frequency & $10 \mathrm{kHz}$ \\
Gain Kp (one cycle) & 0.08 \\
Gain Ki (one cycle) & 0.08 \\
\hline
\end{tabular}

Here we are using two DC motor for system stability. We can control the motor speed given by the load, which are increases or decreases the speed.

Here we have a good benefit, so the important things decreases values of the speed of the motor and it maintains the scenario of the system, no more noises no affection in their system and also PF is good.

Figure 7 THD graph of input current, voltage and output voltage mention RL load and DC motor.

Table 6 The various parameter of one cycle control DC-DC converter measured a value

\begin{tabular}{lccc}
\hline Active power $(P)$ & Apparent power $(s)$ & $P F$ & Current THD \\
\hline 5,338 & 5,365 & 0.99 & $52.30 \%$ \\
\hline
\end{tabular}


Figure 7 (a) Input current with RL load with motor load THD waveform (b) Input voltage (c) Waveforms of speed, armature current, field current and torque of DC motor 1 (d) Waveform of speed, armature current, field current and torque of DC motor 2 (e) Input current (f) Input voltage (g) Output voltage with DC motor and RL load (h) Input current THD (see online version for colours)

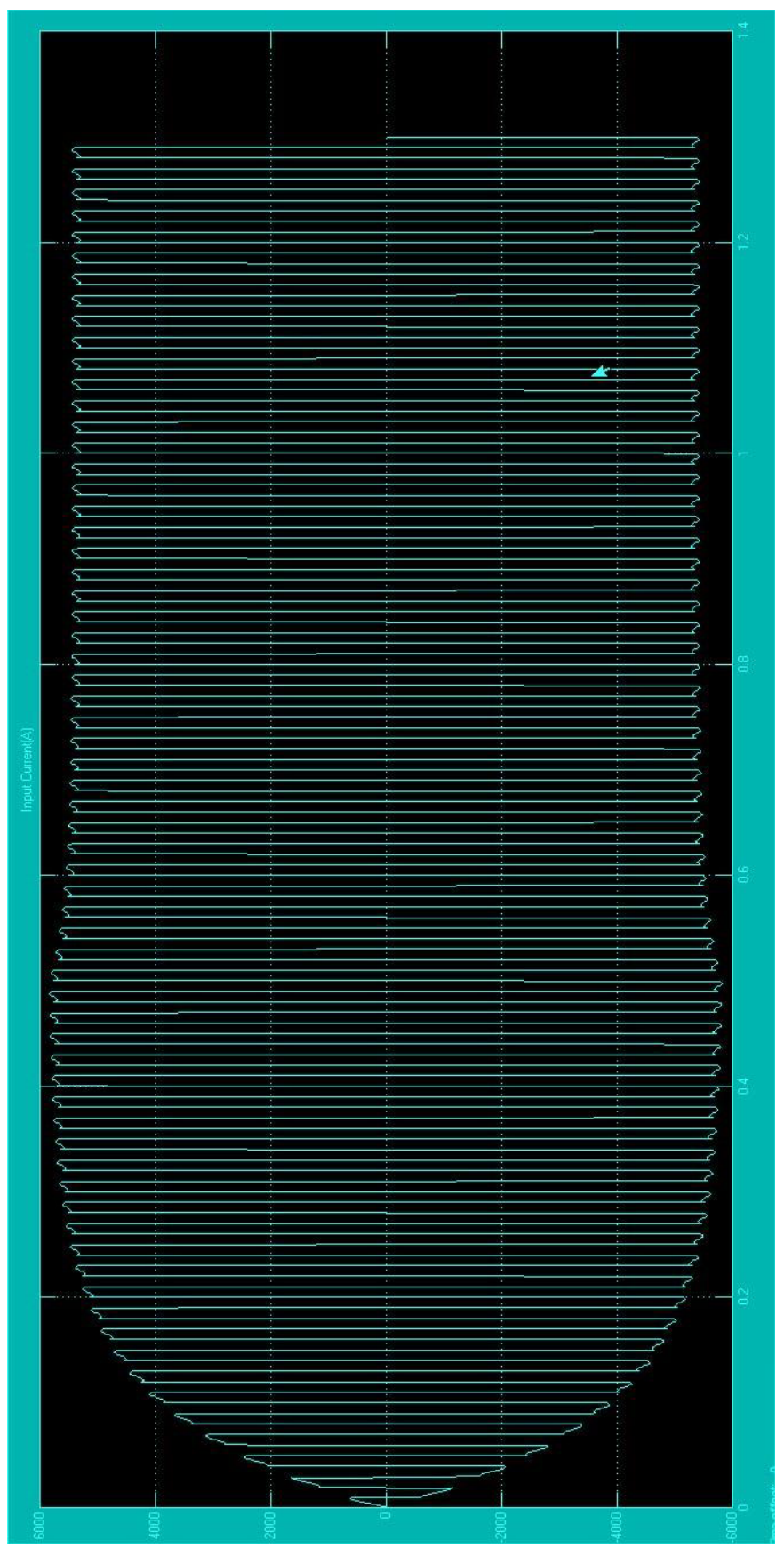

(a) 
Figure 7 (a) Input current with RL load with motor load THD waveform (b) Input voltage (c) Waveforms of speed, armature current, field current and torque of DC motor 1 (d) Waveform of speed, armature current, field current and torque of DC motor 2 (e) Input current (f) Input voltage (g) Output voltage with DC motor and RL load (h) Input current THD (continued) (see online version for colours)

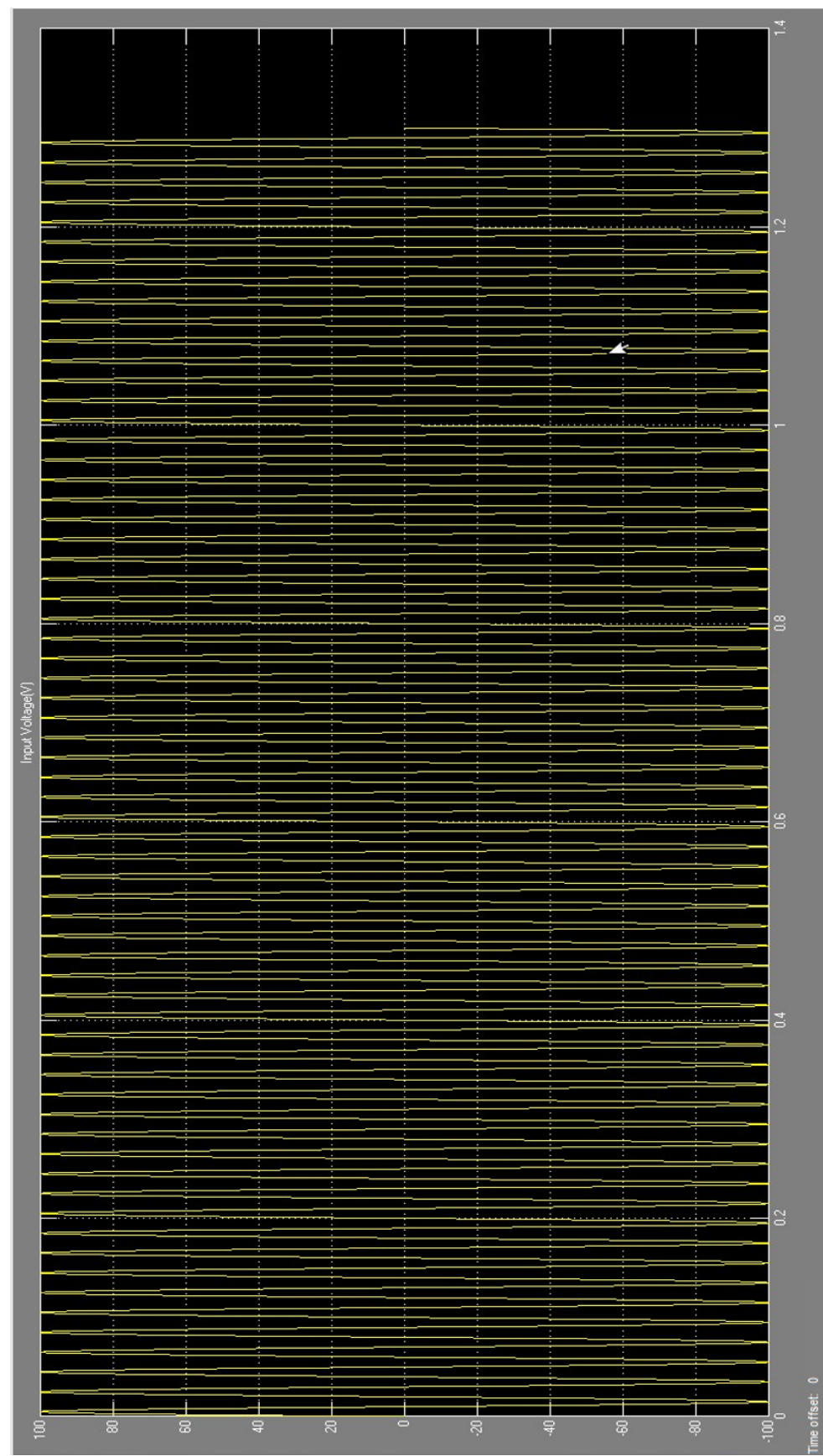

(b) 
Figure 7 (a) Input current with RL load with motor load THD waveform (b) Input voltage (c) Waveforms of speed, armature current, field current and torque of DC motor 1 (d) Waveform of speed, armature current, field current and torque of DC motor 2 (e) Input current (f) Input voltage (g) Output voltage with DC motor and RL load (h) Input current THD (continued) (see online version for colours)

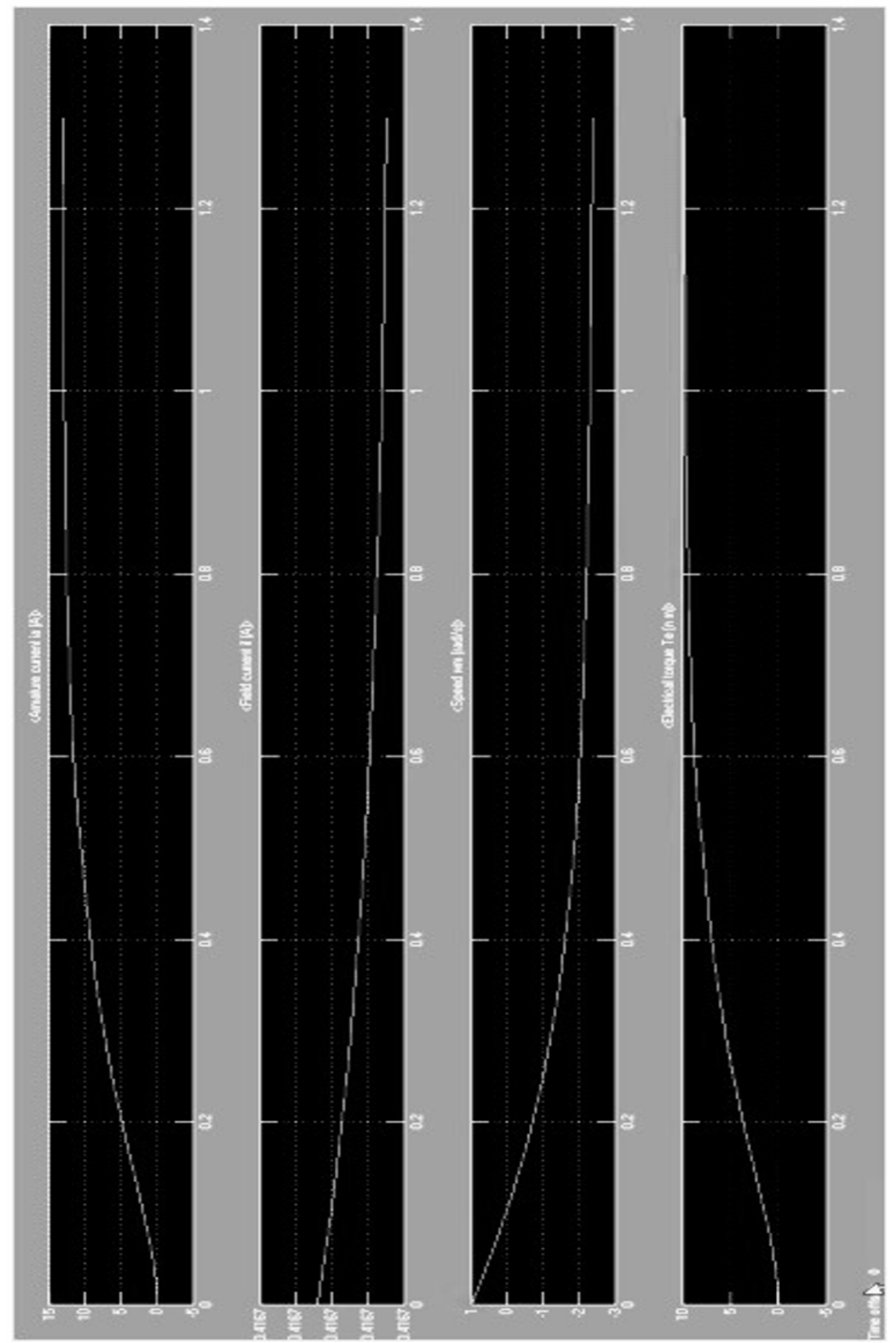

(c) 
Figure 7 (a) Input current with RL load with motor load THD waveform (b) Input voltage (c) Waveforms of speed, armature current, field current and torque of DC motor 1 (d) Waveform of speed, armature current, field current and torque of DC motor 2 (e) Input current (f) Input voltage (g) Output voltage with DC motor and RL load (h) Input current THD (continued) (see online version for colours)

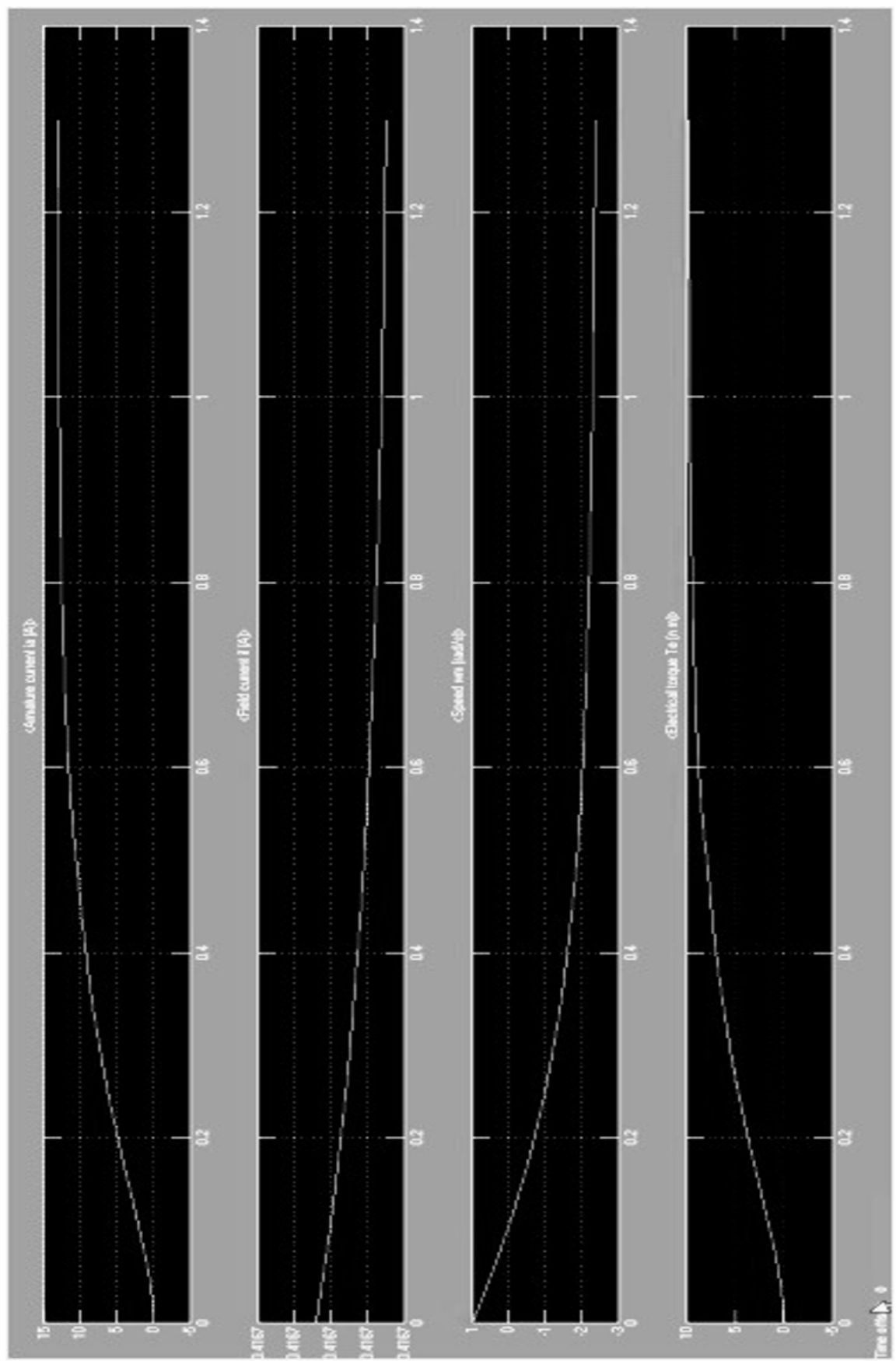

(d) 
Figure 7 (a) Input current with RL load with motor load THD waveform (b) Input voltage (c) Waveforms of speed, armature current, field current and torque of DC motor 1 (d) Waveform of speed, armature current, field current and torque of DC motor 2 (e) Input current (f) Input voltage (g) Output voltage with DC motor and RL load (h) Input current THD (continued) (see online version for colours)

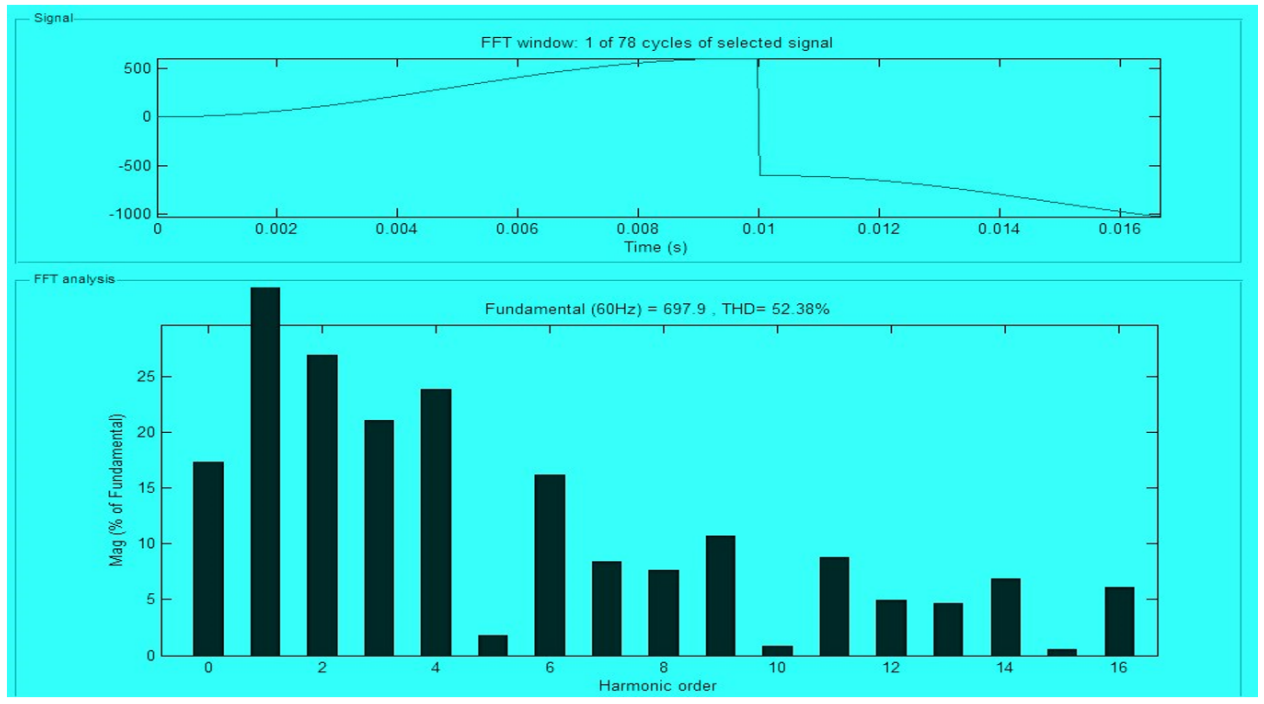

(e)

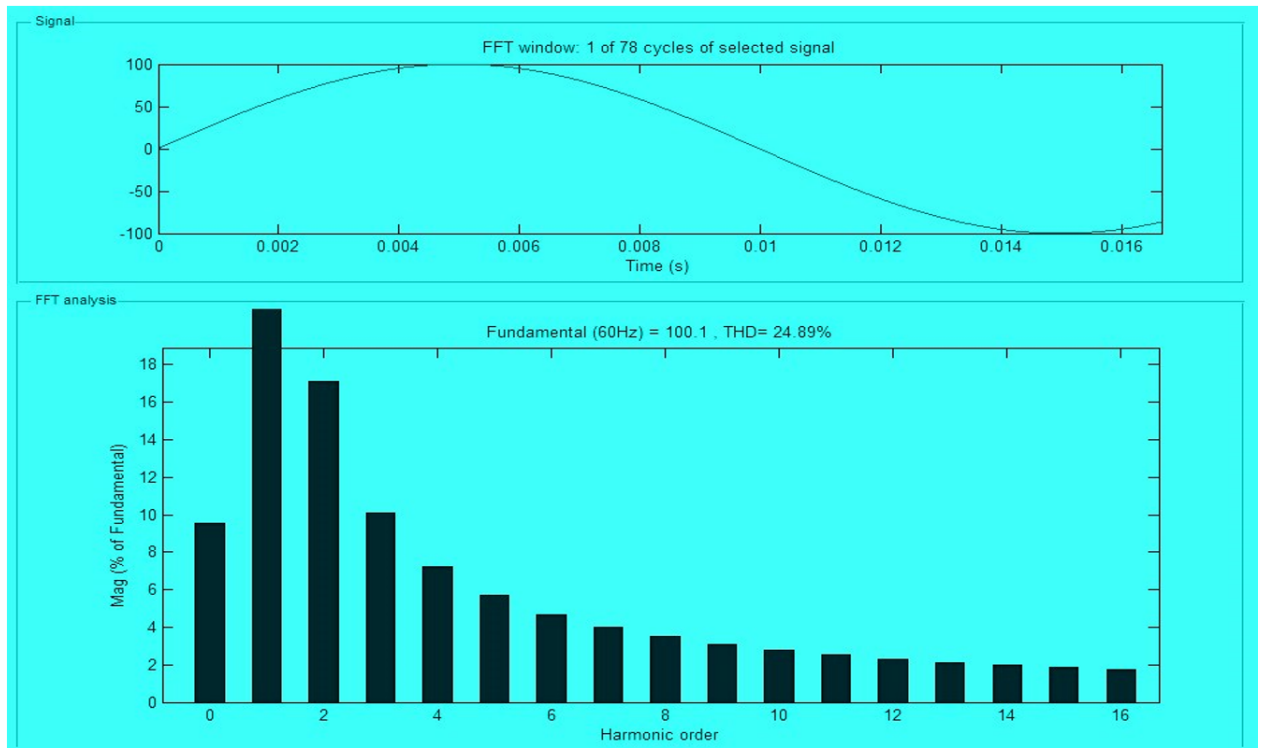

(f) 
Figure 7 (a) Input current with RL load with motor load THD waveform (b) Input voltage (c) Waveforms of speed, armature current, field current and torque of DC motor 1 (d) Waveform of speed, armature current, field current and torque of DC motor 2 (e) Input current (f) Input voltage (g) Output voltage with DC motor and RL load (h) Input current THD (continued) (see online version for colours)

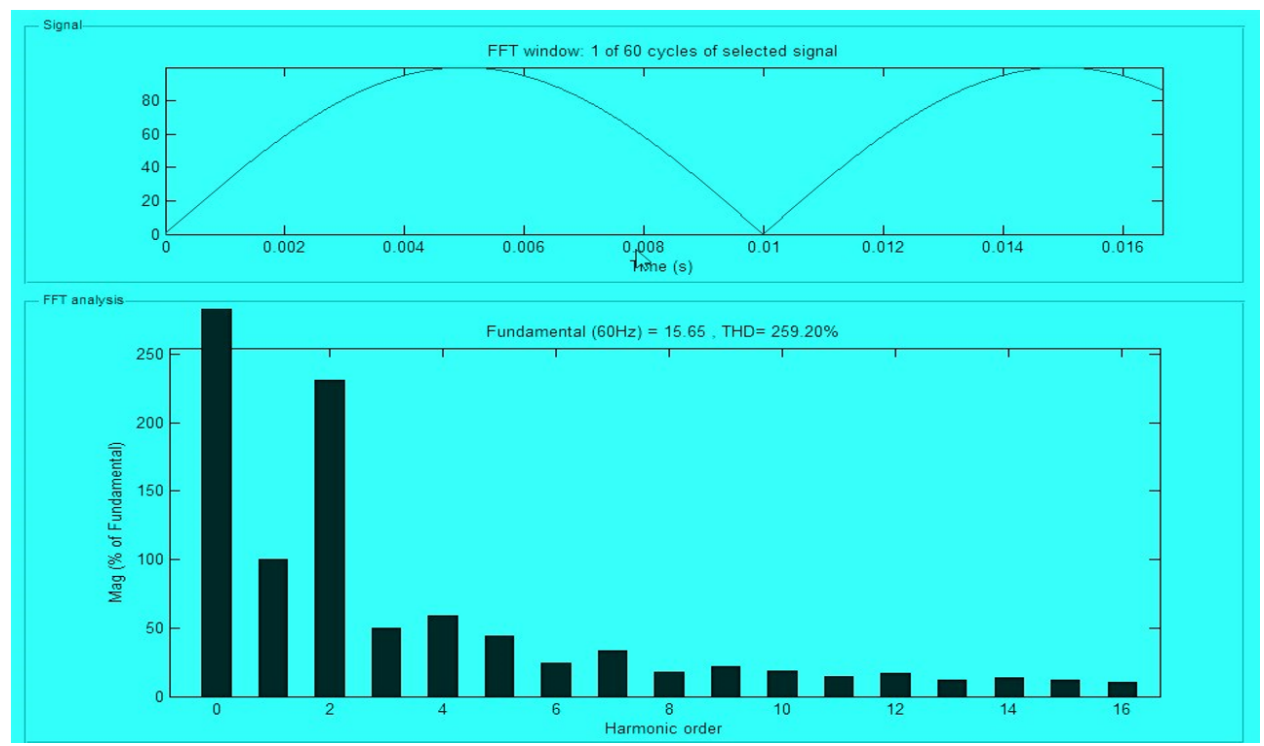

(g)

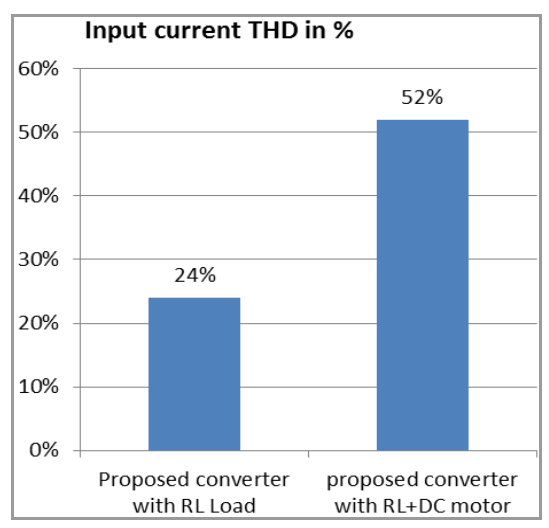

(h)

Its show the how to increase input current THD, when used load and DC motor.

TPF $=$ Displacement $P F \times$ Distortion $P F$

Displacement power factor $=W / V_{A}=\cos \varnothing$

$D P F=1 / \sqrt{1+T H D(I)^{2}}$ 


\section{Conclusions and discussion}

The PFC with different converters is simulated with MATLAB Simulink. In this paper conventional converter, buck converter, boost converter using current mode control are discussed and implemented. The complete performance analysis is done where in FFT analysis and voltage and current output comparison is taken into consideration. It is analysed that the THD is less with boost converter.

The power factor of the boost converter is way better than the other techniques. In this research, we have implemented the model for the system using MATLAB. When THD is increased sometimes power factor decrease. So we found the solution of in this research it quality gain the power factor and also THD. Using PFC with boost and cascaded system and give the better solution. It is also having an advantage; it is given the low price of the gadget in this market. Mainly purpose was to minimise the input current which reduces the THD and improves the power factor and phase change current with voltage.

In future this performance can be further being using with the optimisation, PI and the artificial techniques.

\section{References}

Badawy, M.O., Sozer, Y. and De Abreu-Garcia, J.A. (2016) 'A novel control for a cascaded buck-boost PFC converter operating in discontinuous capacitor voltage mode', IEEE Trans. Ind. Electron., Vol. 63, pp.4198-4210.

Baek, J.I., Kim, J.K., Lee, J.B., Youn, H.S. and Moon, G.W. (2017) 'A boost PFC stage utilized as half-bridge converter for high-efficiency DC-DC stage in power supply unit', IEEE Trans. Power Electron., Vol. 32, pp.7449-7457.

Bang, T. and Park, J.W. (2018) 'Development of a ZVT-PWM buck cascaded buck-boost PFC converter of $2 \mathrm{~kW}$ with the widest range of input voltage', IEEE Trans. Ind. Electron., Vol. 65, pp.2090-2099.

Maksimovic, D. and Cuk, S. (1991) 'Switching converters with wide dc conversion range', IEEE Trans. Power Electron., Vol. 6, No. 1, pp.151-157.

Vishwanathan, N. and Ramanarayanan, V. (2002) Power Electronics Group, Department of Electrical Engineering, Indian Institute of Science, Bangalore - 560 012, India., Average Current Mode Control of High Voltage DC Power Supply for Pulsed Load Application, 0-7803-7420-7/02/\$17.00, IEEE.

Wei, H. and Batarseh, I. (1998) 'Comparison of basic converter topologies for power-factor correction', in Proc. IEEE Southeast Con., pp.348-353.

$\mathrm{Wu}, \mathrm{T}-\mathrm{F}$. and Chen, Y-K. (1999) 'Analysis and design of an isolated single-stage converter achieving power-factor correction and fast regulation', IEEE Transactions on Industrial Electronics, Vol. 46, No. 4, pp.759-767.

Yao, K., Hu, W., Li, Q. and Lyu, J. (2015) 'A novel control scheme of DCM boost PFC converter', IEEE Trans. Power Electron., Vol. 30, pp.5605-5615. 